Research Paper

\title{
Comprehensive evaluation of the efficacy and safety of LPV/r drugs in the treatment of SARS and MERS to provide potential treatment options for COVID-19
}

\author{
Liusheng $\mathrm{Wu}^{1,2,3,{ }^{*}}$, Yuzhen Zheng ${ }^{4,}$, Jixian Liu ${ }^{1,2, \&}$, Ruixing Luo ${ }^{1,2,3}$, Dingwang $\mathrm{Wu}^{2}$, Pengcheng $\mathrm{Xu}^{2}$, \\ Da $\mathbf{W u}^{1,2, \&}$, Xiaoqiang $\mathrm{Li}^{1,2}$ \\ ${ }^{1}$ Peking University Shenzhen Hospital, Clinical College of Anhui Medical University, Shenzhen 518036, Guangdong, \\ China \\ ${ }^{2}$ Department of Thoracic Surgery, Peking University Shenzhen Hospital, Shenzhen 518036, Guangdong, China \\ ${ }^{3}$ Anhui Medical University, Hefei 230032, Anhui, China \\ ${ }^{4}$ Department of Thoracic Surgery, The Sixth Affiliated Hospital, Sun Yat-Sen University, Guangzhou 510655, \\ Guangdong, China \\ *Equal contribution
}

Correspondence to: Da Wu, Jixian Liu, Xiaoqiang Li; email: wuda0125@hotmail.com; 252110465@qq.com; dr.lixiaoqiang@gmail.com, https://orcid.org/0000-0002-9692-1458

Keywords: COVID-19, SARS, MERS, LPV/r, meta-analysis

Received: October 28, $2020 \quad$ Accepted: March 3, 2021

Published: April 20, 2021

Copyright: (C) $2021 \mathrm{Wu}$ et al. This is an open access article distributed under the terms of the Creative Commons Attribution License (CC BY 3.0), which permits unrestricted use, distribution, and reproduction in any medium, provided the original author and source are credited.

\section{ABSTRACT}

Coronavirus disease 2019 (COVID-19) experienced an outbreak that expanded worldwide. Lopinavir/ritonavir (LPV/r), which is used effectively for severe acute respiratory syndrome (SARS) and Middle East respiratory syndrome (MERS) coronavirus infections, was applied for COVID-19 treatment given similarities in the molecular structures of these viruses. We performed a systematic review and meta-analysis to evaluate the efficacy and safety of lopinavir/ritonavir antiviral treatment in patients with SARS, MERS, and COVID-19. After registration with INPLASY, a search was conducted in PubMed, Embase, China National Knowledge Infrastructure (CNKI), Cochrane Library, WanFang Data, China Biomedical Literature Database (CBM) and other databases for all relevant literature on lopinavir/ritonavir treatment of SARS, MERS and COVID-19. The Cochrane Collaboration's bias risk assessment tool and the Newcastle-Ottawa Scale (NOS) were used to evaluate the quality of the literature, and RevMan 5.3 software was used to evaluate the relevant outcome indicators of the efficacy and safety of lopinavir/ritonavir in the treatment of COVID-19. A total of 18 eligible studies (including randomized controlled studies, cohort studies, and case-control studies) were retrieved and included with a total of $\mathbf{2 2 7 3}$ patients. The lopinavir/ritonavir group exhibited an increased nucleic acid conversion rate $(P=0.004)$, higher virus clearance rate $(P<0.0001)$, lower mortality rate $(P=0.002)$, and reduced incidence of acute respiratory distress syndrome (ARDS) $(P=0.02)$ compared with the control group. No significant benefit in the improvement rate of chest $C T(P=0.08)$ or incidence of adverse events $(P=0.45)$ was noted. The lopinavir/ritonavir group had a lower incidence of acute respiratory distress syndrome $(P=0.02)$. According to the clinical prognostic results, the incidence of adverse events between the two groups was not statistically significant $(P<0.0001)$. The efficacy of lopinavir/ritonavir in the treatment of patients with SARS, MERS and COVID-19 was significantly better than that of the control. Furthermore, the incidence of adverse events did not significantly increase. Lopinavir/ritonavir is effective in the treatment of COVID-19, and this combination should be further assessed in RCT studies. In addition, when we analyzed the 


\begin{abstract}
differences in age and sex, we found that the differences were statistically significant in the safety and effectiveness of lopinavir/ritonavir in patients with COVID-19, and both of these factors played a significant role in the trial.
\end{abstract}

\section{INTRODUCTION}

In December 2019, a new type of coronavirus named severe acute respiratory syndrome coronavirus 2 (SARS-CoV-2) caused an outbreak, and it quickly expanded to all over the world. SARS-CoV-2 is a single-stranded, positive-sense RNA virus that belongs to the Orthocoronavirus subfamily of the kingdom Coronaviridae of the order Nidovirales [1-3]. The Orthocoronavirus subfamily can be divided into four genera: $\alpha, \beta, \gamma$ and $\delta$. SARS-CoV-2 belongs to the $\beta$ genus [4]. This virus is a coronavirus that can infect humans and is similar to Middle East respiratory syndrome coronavirus (MERS-CoV) and severe acute respiratory syndrome coronavirus (SARS-CoV). The SARS-CoV-2 genome is similar to that of SARS-CoV and MERS-CoV and exhibits $70 \%$ and $40 \%$ sequence homology with these two viruses, respectively. Some researchers [5-7] used computer molecular docking methods to determine that SARS-CoV-2 and SARS$\mathrm{CoV}$ share certain similarities in the molecular pathways of infected people. Therefore, a summary of previous anti-infective treatment research for SARS and MERS is conducive to identifying an effective treatment for COVID-19. However, the efficacy and safety of many antiviral drugs differ clinically, and COVID-19 treatment has introduced great difficulties.

The SARS outbreak occurred in 2002 and spread to Southeast Asia and the world. It was a global infectious disease epidemic [8] that was gradually eliminated by mid-2003. SARS-CoV has a similar molecular structure to that of SARS-CoV-2, which broke out and spread globally in the beginning of 2020 [9]. Therefore, previous SARS clinical treatment-related research [10] was summarized, analyzing a variety of effective treatment methods and evaluating the efficacy and safety of therapeutic drugs for guiding significance to improve the efficacy of SARS-CoV antivirals. Relevant studies [11-13] have performed clinical bioinformatics analyses on SARS-CoV transcriptome data, explored the mechanism of immune damage omics, collected SARS-CoV transcriptome data in the public gene expression database (Gene Expression Omnibus, GEO) and screened differential genes [14]. Collective analysis and protein interaction analysis were used to explore the mechanism of immune damage related to SARS-CoV infection and apply a precision treatment platform to predict potential therapeutic drugs. Among these drugs, the antiviral drug combination LPV/r achieved good efficacy in the clinical treatment of SARS-CoV, was predicted as a targeted therapeutic regimen and provides a reference for the clinical treatment of COVID-19.

MERS-CoV appeared in Saudi Arabia in 2012 [15]. The epidemic mainly occurred in Middle Eastern countries and South Korea and was occasionally noted in other countries and regions. During the past decade, domestic and foreign medical scientists have conducted a considerable amount of new drug development research for SARS and MERS. To accelerate the discovery of potential treatment options for COVID-19, researchers can learn from experiences with SARS-CoV and MERS$\mathrm{CoV}$ drug development. Based on anti-SARS-CoV and MERS-CoV drug research, research and development costs can be reduced, and the development cycle can be shortened as much as possible. In addition, statistical analyses on related drug clinical trials of MERS antiviral therapy were conducted to evaluate the efficacy and safety of the drug and accumulate information for the treatment of current patients with COVID-19.

Lopinavir/ritonavir $\left(\mathrm{LPV} / \mathrm{r}\right.$, Kaletra ${ }^{\circledR}$ or Aluvia $\left.{ }^{\circledR}\right)$ is a protease inhibitor combination developed by AbbVie in the United States and was approved by the US Food and Drug Administration in 2000 to treat human immunodeficiency virus type 1 (HIV-1). Although the main indication of LPV/r is HIV-1 infection [16], clinical data [17] demonstrate that LPV/r can significantly reduce the mortality of patients infected with SARS-CoV, and this drug has cured patients infected with SARS-CoV and MERS-CoV in previous case reports. LPV/r is also the first anti-HIV-1 drug reported to be used in the clinical treatment of SARS-CoV-2 infection [17, 18].

However, the efficacy and safety of LPV/r in the treatment of patients with COVID-19 are very controversial. Cao et al. [19] reported that LPV/r has poor therapeutic efficacy in patients with severe COVID-19, and there are serious complications, such as ARDS. In addition, numerous clinical trials of LPV/r in the treatment of patients with early, mild COVID-19 have shown good therapeutic effects, and the results indicate that the incidence of adverse events was not statistically significant. In addition, there are significant differences in the efficacy and safety of LPV/r treatment in patients of different races and different ages and even in patients with different underlying diseases (including diabetes, HIV infection, and hepatitis B infection) $[20,21]$. Therefore, to solve the abovementioned 
problems, a meta-analysis was conducted to evaluate the clinical research objectively and systematically on $\mathrm{LPV} / \mathrm{r}$ in the treatment of SARS, MERS and COVID-19 and comprehensively evaluate the efficacy and safety of $\mathrm{LPV} / \mathrm{r}$. This study provides guidance on the antiviral treatment of COVID-19.

In clinical trials of many drugs, researchers consider many factors. The patient age range is often set to 18 to 65 years, which limits the inclusion of elderly people (>65 years old) and also leads to the loss of the opportunity to study the different effects based on aging populations in drug trials.

Mikhail V Blagosklonny claim that mortality increases exponentially with age, which is the strongest predictor of mortality in COVID-19 [22]. Mortality is higher in men compared with women because men age faster, and it is especially high in patients with age-related diseases. These diseases are manifestations of aging and a measure of biological age.

Camillo Sargiacomo [23] published a study on COVID19 and chronological aging in the journal Aging-US, and he hypothesized that anti-aging drugs would be effective for the treatment or prevention of coronavirus infection. Therefore, he suggests that the fight against COVID-19 disease should involve testing the hypothesis that anti-aging drugs may have a prominent role in preventing the transmission of the virus.

\section{MATERIALS AND METHODS}

\section{Literature search strategy}

A request to register the present systematic review was submitted to INPLASY (INPLASY22080007) on July 20, 2020. The two researchers independently conducted systematic literature searches on PubMed, Cochrane Library, Embase and clinical trial registry platforms (http://clinicaltrials.gov/and http://www.chictr.org.cn/). Trials from the establishment of the database to July 2020 were included. The document language was limited to English and Chinese. We set the search keywords as follows: ("COVID-19" OR "SARS-CoV2" OR "SARS-CoV" OR "MERS-CoV") AND ("lopinavir/ritonavir" OR "LPV/r"). Article types included randomized controlled trials (RCTs), cohort studies, and case-control studies. The references of the included studies and review articles were also reviewed to identify additional relevant studies.

\section{Inclusion criteria and exclusion criteria}

(1) Participants: patients with positive nucleic acid test results for SARS, MERS or COVID-19; (2)
Intervention method: use of LPV/r for antiviral therapy; (3) Controlled study: use of other antiviral drugs or lack of use of LPV/r for antiviral therapy; (4) Research outcome: virus nucleic acid conversion rate, chest CT improvement rate, virus clearance rate, mortality rate, incidence of adverse events (AE), etc. (5) Research type: randomized controlled trials (RCTs), cohort studies, and case-control studies.

\section{Quality evaluation and data extraction}

Two investigators independently evaluated the quality of the trials and extracted data. According to the standards in the Cochrane Handbook for Systematic Reviews of Interventions, the quality of the trial was evaluated based on the following aspects: selection bias, implementation bias, measurement bias, follow-up bias, reporting bias and other potential sources of bias. The extracted content was as follows: (1) basic information of the article, such as author and publication year; (2) research design: treatment path, treatment plan, number of patients in each group, administration method, dominant race, etc.; (3) observation results: viral nucleic acid conversion rate, chest data indicators, CT improvement rate, virus clearance rate and mortality rate and $95 \% \mathrm{CI}, \mathrm{OR}, \mathrm{RR}$ and $\mathrm{AE}$ incidence. The two researchers discussed and resolved their differences. If they could not reach an agreement, the third researcher decided.

\section{Data extraction}

Stata 12.0 (Stata Corp, College Station, TX, USA) and RevMan 5.3 (The Nordic Cochrane Centre, Copenhagen, Denmark) were used to calculate the relative risk (RR) and 95\% CI of ORs and AEs. Egger's linear regression analyses and funnel plots were used to assess publication bias, and a Q test was used for heterogeneity analyses. The $\mathrm{I}^{2}$ statistic was used to assess the level of heterogeneity among studies. When $\mathrm{I}^{2}$ was $>50 \%$, the heterogeneity was considered significant, and a random effects model was used for analysis. Otherwise, a fixed effects model was used. Subgroup analysis was used to investigate possible sources of heterogeneity: dominant race, administration method and treatment route. If heterogeneity could not be eliminated by the subgroup analysis, a sensitivity analysis was performed to further determine the source of heterogeneity. All Pvalues were two-sided tests. $\mathrm{P}<0.05$ was considered statistically significant.

\section{Ethics approval}

Ethics approval was not required for this systematic review. 


\section{RESULTS}

\section{Literature retrieval results and basic characteristics of the included studies}

The preliminary retrieval identified 4731 articles and excluded 3486 articles, including duplicates, irrelevant studies and articles with insufficient data. Among the remaining 1245 articles, 1043 articles, including case reports, basic research, and animal experiments, were excluded. Of the remaining 202 articles, 184 articles were eliminated by the Jadad score and NOS score for literature quality. Finally, 18 articles [19, 21, 22, 24-38] including 2273 patients were successfully included in the study (Supplementary Table 1). The literature screening process and results are shown in Figure 1, and the basic characteristics of the studies are shown in Supplementary Table 1.
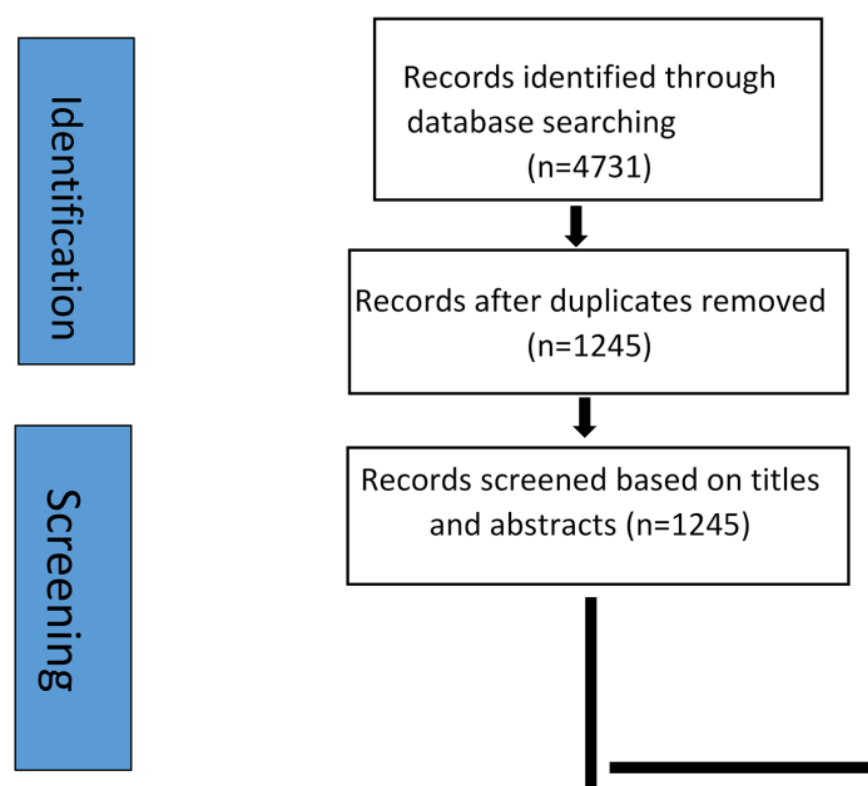

Records screened based on titles and abstracts $(n=1245)$
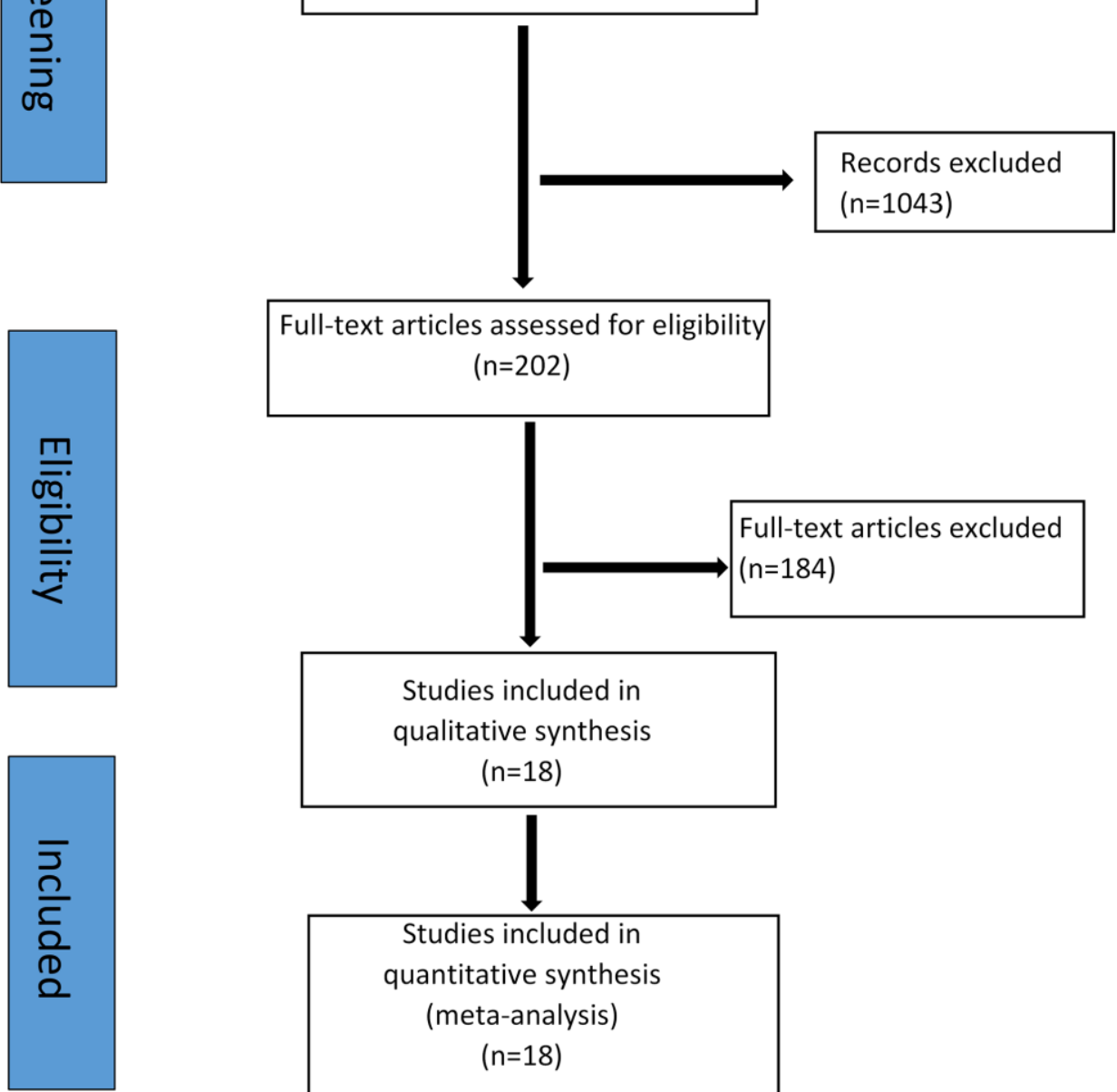

Figure 1. Flow chart of the literature search and study selection procedure. 
Our study collected ongoing studies on LPV/r drug clinical trials (Supplementary Table 2). A total of 15 clinical trial studies on LPV/r for the treatment of COVID-19 included 6 single-drug regimens and 9 combination regimens. We found that an increasing number of trials have explored and evaluated LPV/r in combination with other drugs to treat COVID-19, providing increasingly effective options for patients with COVID-19.

\section{Risk of bias and quality of evidence assessment}

According to the Cochrane Systematic Review Manual (version 5.1.0), two investigators independently assessed the risk of bias in the included studies. The overall methodological quality of the 18 articles was good and fair. The GRADE working group evaluated the quality of evidence for each result. Mortality and adverse events (AEs) had a high level of evidence, the nucleic acid conversion rate had an intermediate level of evidence, and the virus clearance rate and chest $\mathrm{CT}$ improvement rate had a low level of evidence (Figures 2, 3).

Our study evaluated the quality assessment of 18 articles. We found performance bias of blinding of participants and personnel and detection bias of blinding of outcome assessment. Figures 2, 3 present the quality assessment of the literature in our studies. The green label indicates a low risk of bias, the yellow label indicates an unclear risk of bias, and the red label indicates a high risk of bias.

Based on the risk of bias graph, we observed a low risk of selection bias and attrition bias but still a high risk of performance bias in 18 studies.
From the risk of bias summary, we observe both the overall distribution of bias risk and the degree of bias risk in each research study. There may be concentrated in the overall risk bias, but it is a very small proportion in each individual study.

\section{Evaluation of the effectiveness of $\mathrm{LPV} / \mathrm{r}$ in the treatment of SARS, MERS and COVID-19}

\section{Nucleic acid conversion}

A total of 6 studies $[19,29,30,34,35]$ reported data on the nucleic acid conversion rate with LPV/r clinical treatment (the 6 trials were all COVID-19 studies). Egger's test $(\mathrm{P}=0.15)$ and the funnel plot did not demonstrate significant publication bias. The heterogeneity test revealed that there was no significant heterogeneity among the trials $\left(\mathrm{I}^{2}<50 \%\right)$, and the fixed effects model was used for statistical analysis. The results showed that the LPV/r experimental group [71.7\% (109/152)] was significantly better than the control group without $\mathrm{LPV} / \mathrm{r}$ or other antiviral drugs [58.8\% (94/160)] in the treatment of COVID-19 [OR=2.22, 95\% CI: 0.67 6.44, P=0.004] (Figure 4).

\section{Mortality rate}

The 18 included articles had mortality data for LPV/r treatment (SARS: 3 articles, MERS: 3 articles, and COVID-19: 12 articles). Egger's test $(\mathrm{P}=0.084)$ and the funnel plot did not demonstrate publication bias. The heterogeneity test revealed no significant heterogeneity among the trials $\left(\mathrm{I}^{2}=0 \%\right)$, and the fixed effects model was used for synthetic analysis. The results showed that the LPV/r experimental group [3.69\% (20/542)] had significantly lower mortality in

Random sequence generation (selection bias)

Allocation concealment (selection bias)

Blinding of participants and personnel (performance bias)

Blinding of outcome assessment (detection bias)

Incomplete outcome data (attrition bias)

Selective reporting (reporting bias)

Other bias
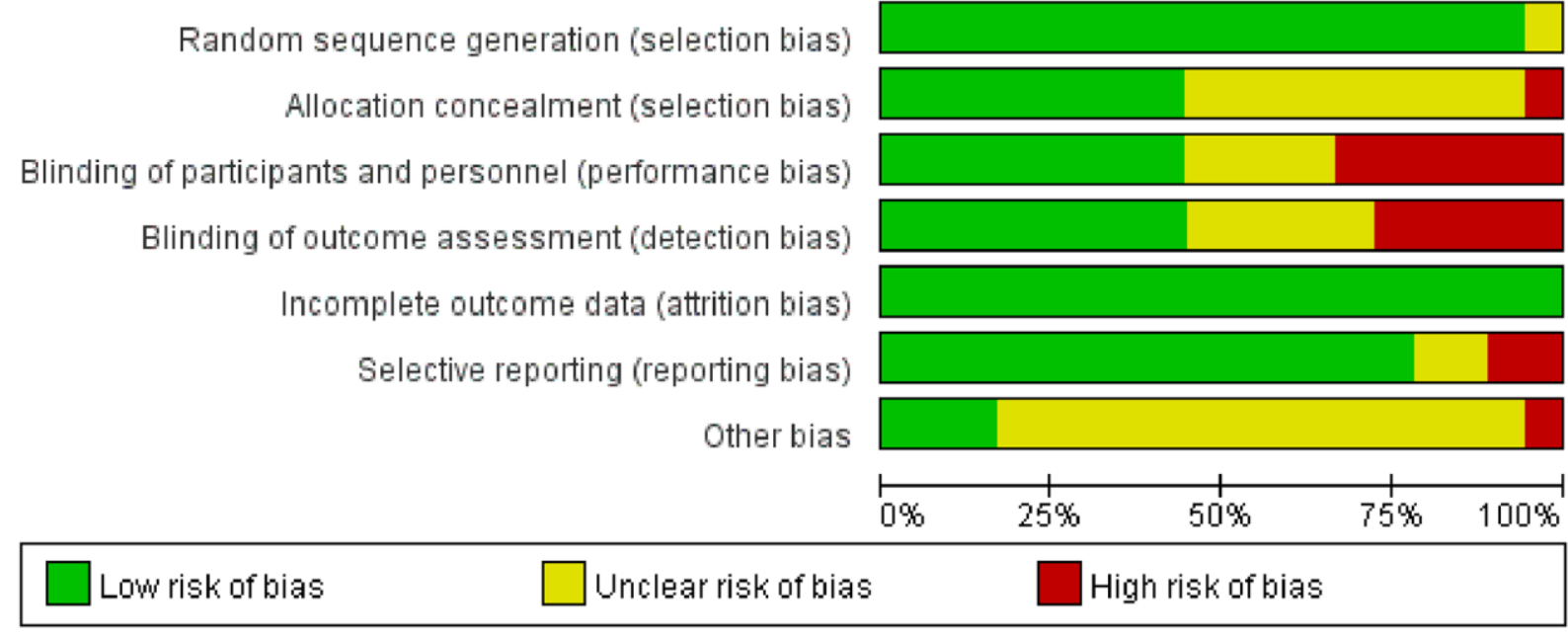

Figure 2. Risk of bias graph. 


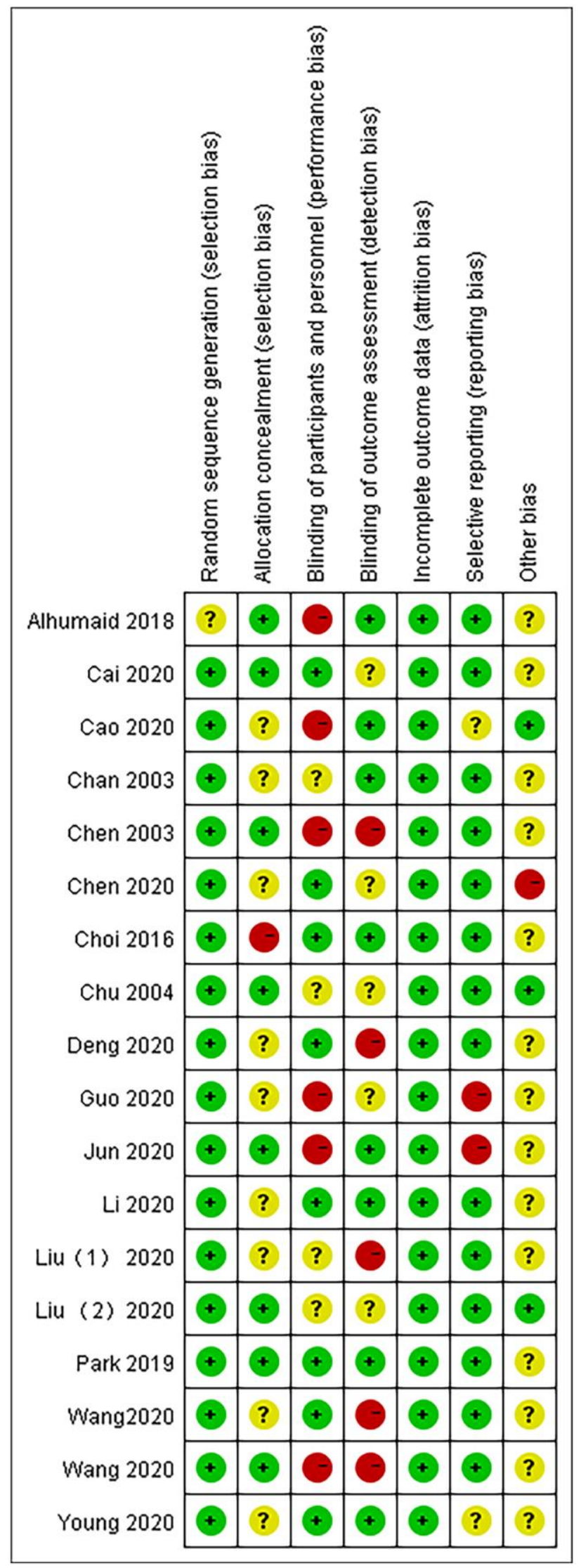

Figure 3. Risk of bias summary. patients with SARS, MERS or COVID-19 compared with the control group [7.97\% (138/1731)], and the clinical treatment effect was significantly better [OR=0.43, 95\% CI: 0.25 0.73, P=0.002] (Figure 5).

\section{Virus clearance rate}

Five studies [22, 25, 29, 32, 36] reported data on virus clearance rates (SARS: 1 article, MERS: 1 article, and COVID-19: 3 articles). Egger's test and the funnel plot did not demonstrate publication bias. The heterogeneity test revealed significant heterogeneity among the trials $\left(\mathrm{I}^{2}=83 \%\right)$. To explore the source of heterogeneity, race, age and severity of the disease, which may have been related to the heterogeneity, were included in the study. A fixed effects model was used for synthetic analysis. The results showed that the LPV/r experimental group [79.17\% (228/288)] had significant virus clearance in the antiviral clinical treatment of SARS, MERS and COVID19 compared to the control group [58.13\% (218/375)] [OR=2.39, 95\% CI: 1.68 3.39, $\mathrm{P}<0.00001]$ (Figure 6).

\section{Chest CT improvement rate}

A total of 7 studies [22, 26, 28, 29, 32, 33, 36] reported relevant data on the chest CT improvement rate with LPV/r treatment (SARS: 1 article, MERS: 1 article, and COVID-19: 5 articles). Egger's test $(\mathrm{P}=0.084)$ and the funnel plot did not demonstrate publication bias. The heterogeneity test revealed significant heterogeneity $\left(\mathrm{I}^{2}=67 \%\right)$ among the 7 trials. A fixed pattern was used to analyze the heterogeneity, and the source of the heterogeneity was traced. The source may differ from the underlying diseases (diabetes, HIV infection, hepatitis B infection, etc.). The results showed no statistically significant differences between the LPV/r experimental group and the control group $[R R=1.00$, 95\% CI: 0.96 1.32, $\mathrm{P}=0.08$ ] (Figure 7).

\section{Safety assessment of LPV/r treatment for SARS, MERS and COVID-19}

\section{ARDS}

A total of 4 studies [22, 25, 26, 29] reported data on ARDS for LPV/r treatment (SARS: 1 article, MERS: 2 articles, COVID-19: 1 article). The heterogeneity test demonstrated that there was no significant heterogeneity among the trials $\left(\mathrm{I}^{2}=0 \%\right)$, and a fixed effects model was used for analysis. The results showed that the LPV/r experimental group [18.87\% (47/249)] effectively reduced the incidence of ARDS compared with the control group [40\% (34/85)]. The safety assessment was high, and the difference was statistically significant [OR=0.46, 95\% CI: $0.25 \sim 0.87, \mathrm{P}=0.02]$.

\section{Adverse events (AEs)}

A total of 6 studies [30, 31, 33-35, 38] reported adverse events (AEs) during LPV/r treatment (COVID-19: 6 
articles). Egger's test and the funnel plot did not demonstrate publication bias. The heterogeneity test revealed no significant heterogeneity among the trials (I2 $=0 \%$ ), and a fixed effects model was used for analysis. The results showed that the difference between the LPV/r experimental group [26.81\% (85/317)] and the control group [27.48\% (97/353)] was not statistically significant [OR=0.87, 95\% CI: 0.60 1.25, $\mathrm{P}=0.45]$.

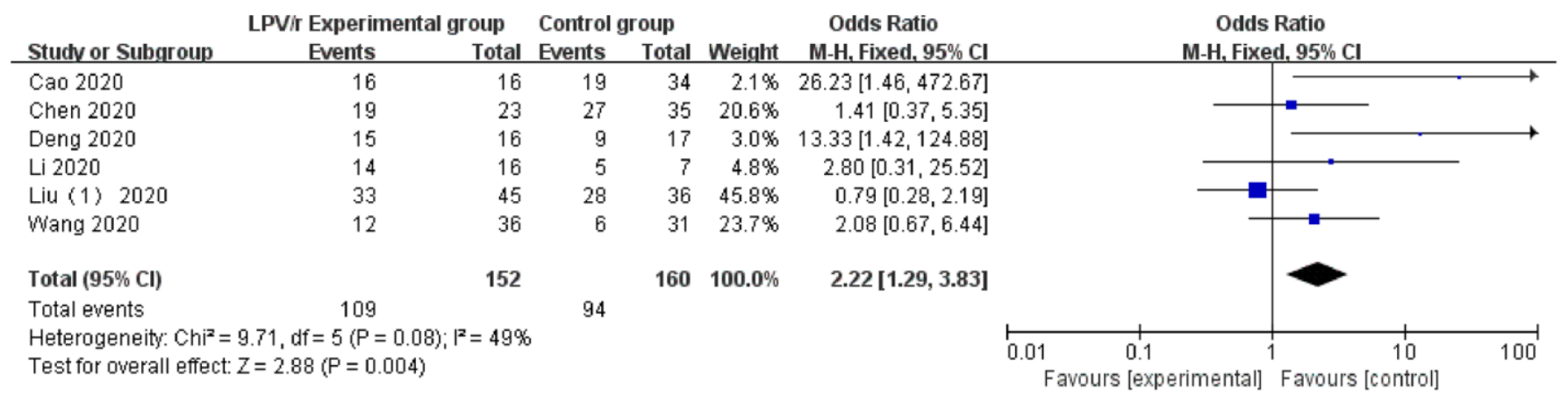

Figure 4. Forest plot of the meta-analysis of nucleic acid conversion.

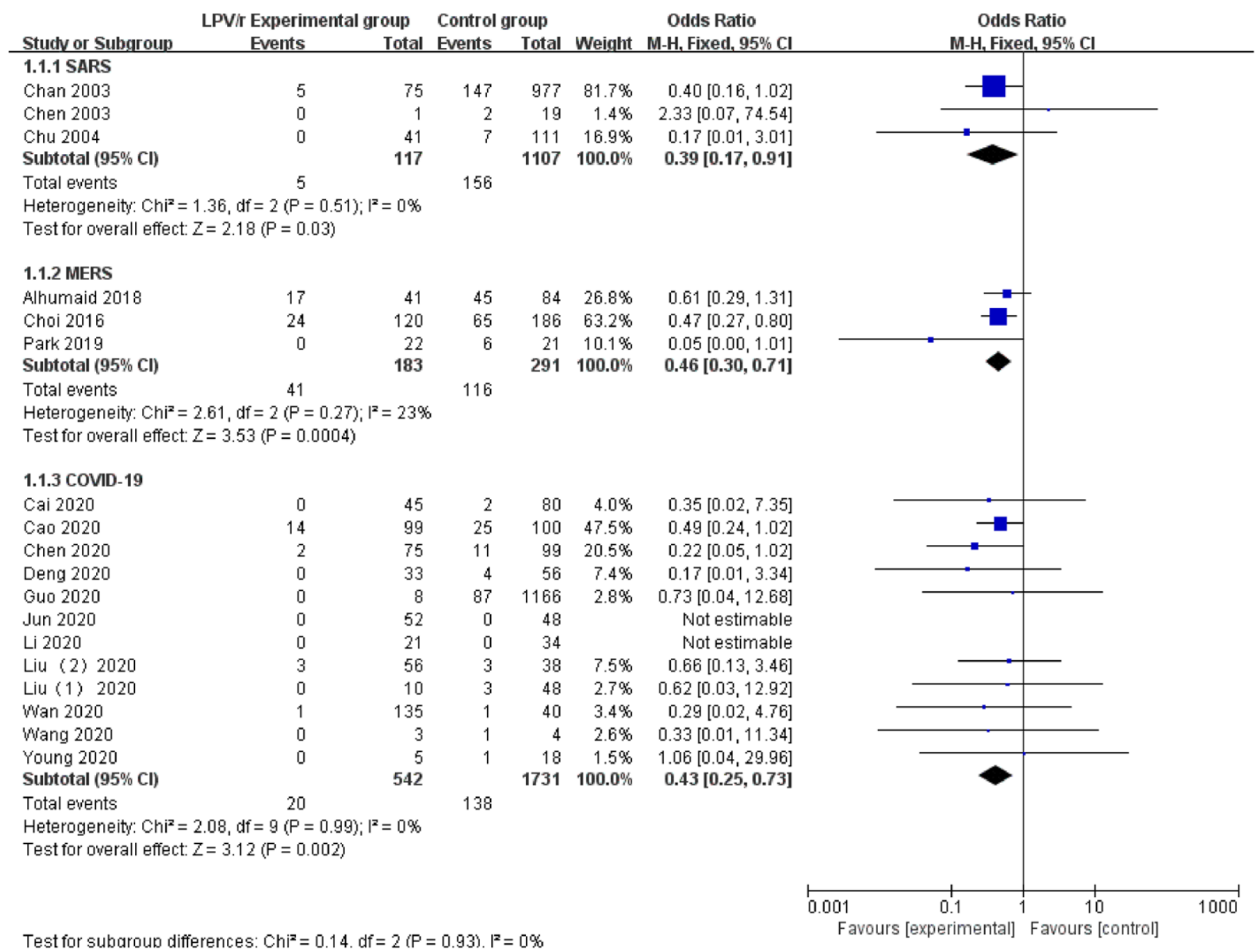

Figure 5. Forest plot of the meta-analysis of the mortality rate. 
Intubation and mechanical ventilation

A total of 3 studies [24, 25, 27] reported data on intubation and mechanical ventilation in LPV/r therapy (SARS: 1 article and MERS: 2 articles). The heterogeneity test demonstrated no significant heterogeneity among the trials $\left(\mathrm{I}^{2}=0 \%\right)$, and a fixed effects model was used for analysis. The results showed that the LPV/r experimental group [29.53\% (44/149)] had a higher intubation rate and proportion of mechanical ventilation compared with the control group [4.27\% (29/679)], but the difference was not statistically significant $[\mathrm{OR}=0.60,95 \%$ CI: $0.27 \sim 1.34, \mathrm{P}=0.22]$.

\section{Leukopenia}

A total of 5 studies $[25,26,29,32,38]$ reported data on leukopenia in LPV/r antiviral therapy (MERS: 2 articles and COVID-19: 3 articles). The heterogeneity test demonstrated significant heterogeneity among the trials $\left(\mathrm{I}^{2}=67 \%\right)$, and a fixed effects model was used for analysis. The results showed no statistically significant differences between the two groups $[\mathrm{OR}=0.83,95 \% \mathrm{CI}$ : $0.53 \sim 1.29, \mathrm{P}=0.40]$.

\section{Anemia}

A total of 4 studies $[28,34,35,37]$ reported data on the occurrence of anemia with LPV/r antiviral therapy

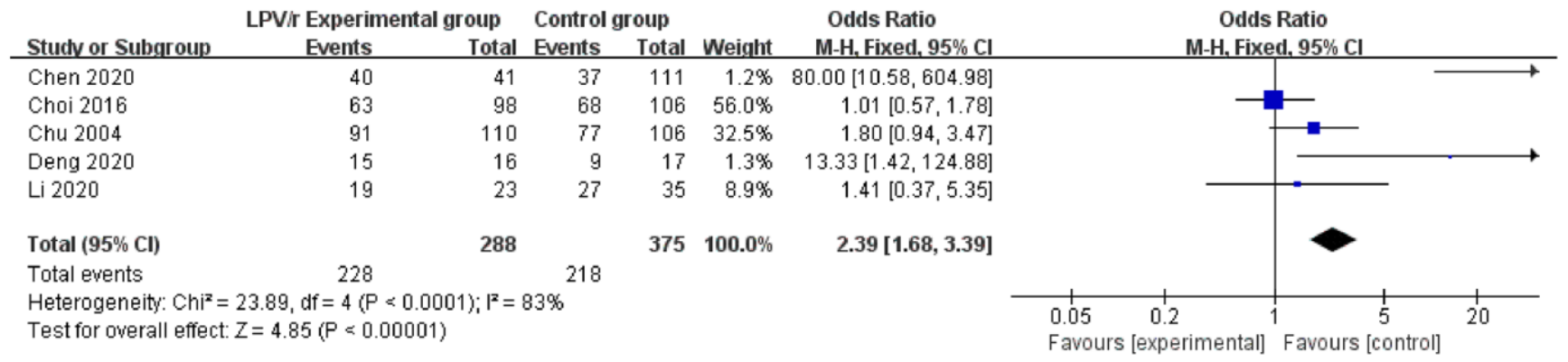

Figure 6. Forest plot of the meta-analysis of the virus clearance rate.

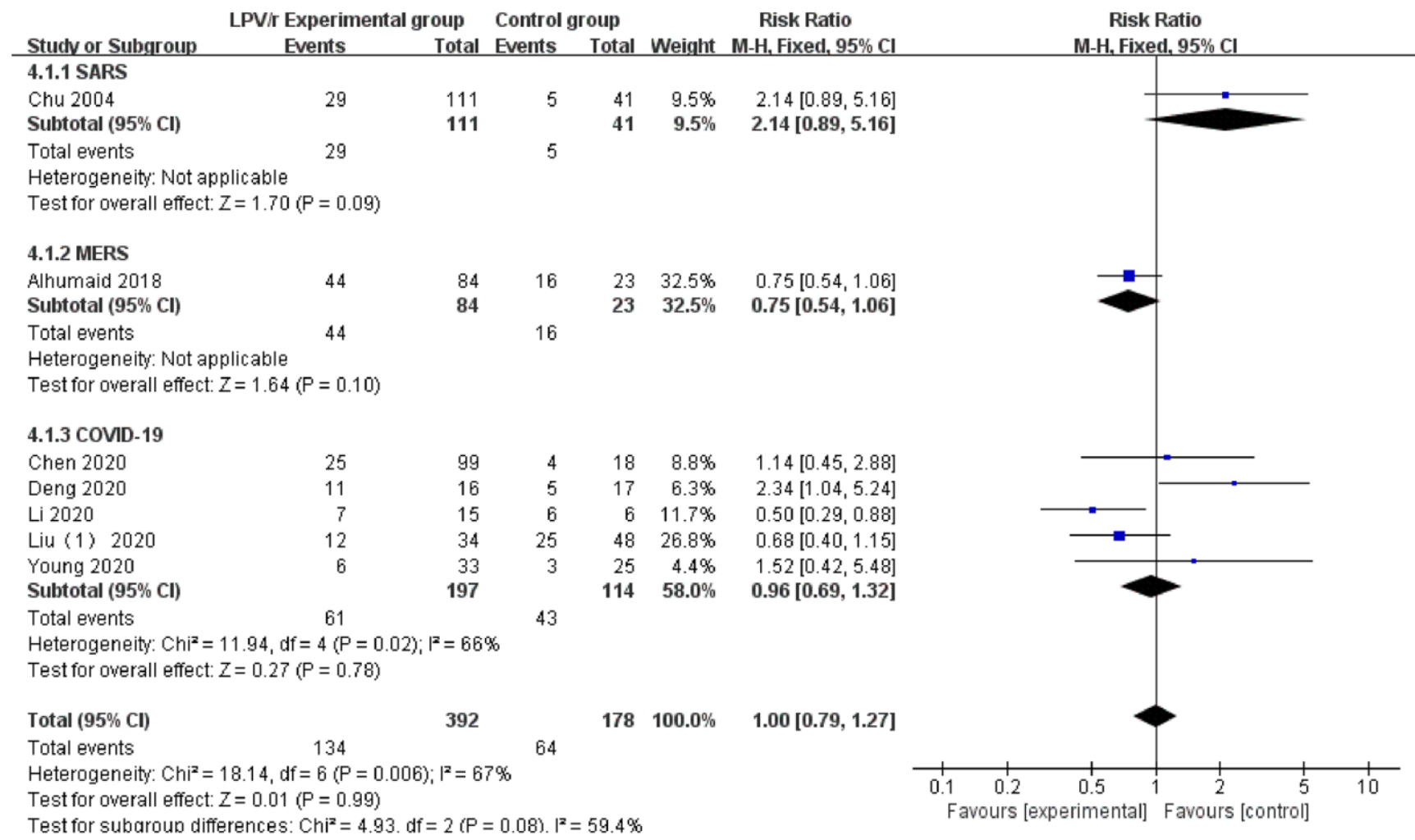

Figure 7. Forest plot of the meta-analysis of the chest CT improvement rate. 
(COVID-19: 4 articles). The heterogeneity test demonstrated significant heterogeneity among the trials $\left(\mathrm{I}^{2}=85 \%\right)$, and a fixed effects model was used for analysis. The results showed that the incidence of anemia in the LPV/r experimental group [39\% (126/323)] was significantly greater than that in the control group [15\% (45/300)], suggesting that there are complications of anemia when using LPV/r for antiviral therapy. The difference between the two groups was statistically significant $[\mathrm{OR}=3.45,95 \% \mathrm{CI}: 2.30 \sim 5.17, \mathrm{P}<0.001]$.

\section{Thrombocytopenia}

A total of 2 studies $[26,38]$ reported the occurrence of thrombocytopenia with LPV/r antiviral therapy (MERS: 1 article and COVID-19: 1 article). Egger's test and the funnel plot did not demonstrate publication bias. The heterogeneity test revealed no significant heterogeneity between the trials $\left(\mathrm{I}^{2}=0 \%\right)$, and a fixed effects model was used for analysis. The results showed that the difference between the two groups was not statistically significant $[\mathrm{OR}=0.73,95 \%$ CI: 0.35 1.51, $\mathrm{P}=0.40$ ] (Figure 8).

\section{Age-based differences in LPV/r therapy in patients with COVID-19}

We collected and organized the clinical data of COVID19 patients treated with LPV/r as much as possible in the 18 RCTs of our study and separately analyzed the available age data of patients. There were two groups: the elderly patient group (age $>65$ years) and the nonelderly patient group (age $<65$ years). In addition, we also added the influencing factors of cardiopulmonary disease to analyze the role and effect of aging in the LPV/r treatment of COVID-19, and the data indicated that aging plays a significant role in $\mathrm{LPV} / \mathrm{r}$ treatment of COVID-19.

In terms of efficacy, in the application of LPV/R against COVID-19, the nonelderly patients group exhibited more advantages than the elderly patients group in terms of efficacy: nucleic acid conversion $(\mathrm{OR}=0.20$, 95\% CI:0.13 0.32, $\mathrm{P}<0.00001)$, mortality rate $(\mathrm{OR}=5.57,95 \% \mathrm{CI}: 1.63 \sim 19.08, \mathrm{P}=0.006)$, and virus clearance rate $(\mathrm{OR}=0.37,95 \% \mathrm{CI}: 0.18 \sim 0.76, \mathrm{P}=0.007)$. However, in terms of the chest $\mathrm{CT}$ improvement rate $(\mathrm{OR}=1.19,95 \%$ CI: 0.59 2.41, $\mathrm{P}=0.63)$, no significant difference was noted between the two groups $(\mathrm{P}>0.05)$.

In terms of safety, in the nonelderly patient group and the elderly patient group, more distinctly different complications were noted after treatment with $\mathrm{LPV} / \mathrm{r}$, and the difference was statistically significant $(\mathrm{P}<0.05)$.

The data showed that compared with the nonelderly patients group, the elderly patients group treated with
$\mathrm{LPV} / \mathrm{r}$ was more likely to cause ARDS (OR $=4.84,95 \%$ CI:1.52 15.41, $\mathrm{P}=0.008)$ and AEs $(\mathrm{OR}=2.69,95 \%$ $\mathrm{CI}: 1.15 \sim 6.29, \quad \mathrm{P}=0.02)$. However, there was no significant difference in intubation and mechanical ventilation $(\mathrm{OR}=1.74,95 \% \mathrm{CI}: 0.83 \sim 3.64, \mathrm{P}=0.14)$, leukopenia $(\mathrm{OR}=1.31,95 \%$ CI:0.47 3.67, $\mathrm{P}=0.61)$, anemia $(\mathrm{OR}=1.75,95 \% \mathrm{CI}: 0.43 \sim 7.07, \mathrm{P}=0.43)$ and thrombocytopenia $\quad(\mathrm{OR}=1.34, \quad 95 \% \quad \mathrm{CI}: 0.53 \sim 3.39$, $\mathrm{P}=0.53$ ) (Figure 9).

\section{Sex-based differences in LPV/r therapy of patients with COVID-19}

Our study analyzed the data of sex-based differences in the research projects, and we considered that some clinical projects have the following problems: 1 . The establishment of the control group was not unified; 2 . Partial data loss was noted in the research; 3. Inconsistent evaluation criteria were employed for efficacy indicators.

We previously reviewed many studies. We found that in the treatment of some HIV patients with LPV/r, some scholars use immune cells (mainly CD-4+ $\mathrm{T}$ lymphocytes) as the efficacy indicator of LPV/r, but few studies have reported sex differences in LPV/r in antiviral therapy. However, we analyzed the gender data of patients included in the study group. There was a significant difference in LPV/r in the antiviral process of COVID-19 patients, and the difference was statistically significant $(\mathrm{OR}=1.58,95 \% \mathrm{CI}: 1.28 \sim 1.95, \mathrm{P}<0.0001)$.

Some selection bias may also be noted. For example, in compliance with the randomized control principle, patients with COVID-19 were included in the study groups instead of following the strict selection criteria of a 1:1 male to female ratio, which may also have had an impact on the statistical results (Figure 10).

\section{Publication bias}

The funnel plot of literature publication bias was symmetric, and all literature research experiments were controlled within the $95 \%$ confidence interval, indicating that there was no significant publication bias among the included studies.

Taking the nucleic acid conversion rate of COVID-19 patients treated with LPV/R drug as an example, Begg's test $(\mathrm{P}<0.001)$ and Egger's test $(\mathrm{P}=0.989)$ indicated no obvious publication bias (Figure 11).

\section{DISCUSSION}

$\mathrm{LPV} / \mathrm{r}$ is widely used in the first-line treatment of respiratory virus infections and HIV infection. Some 


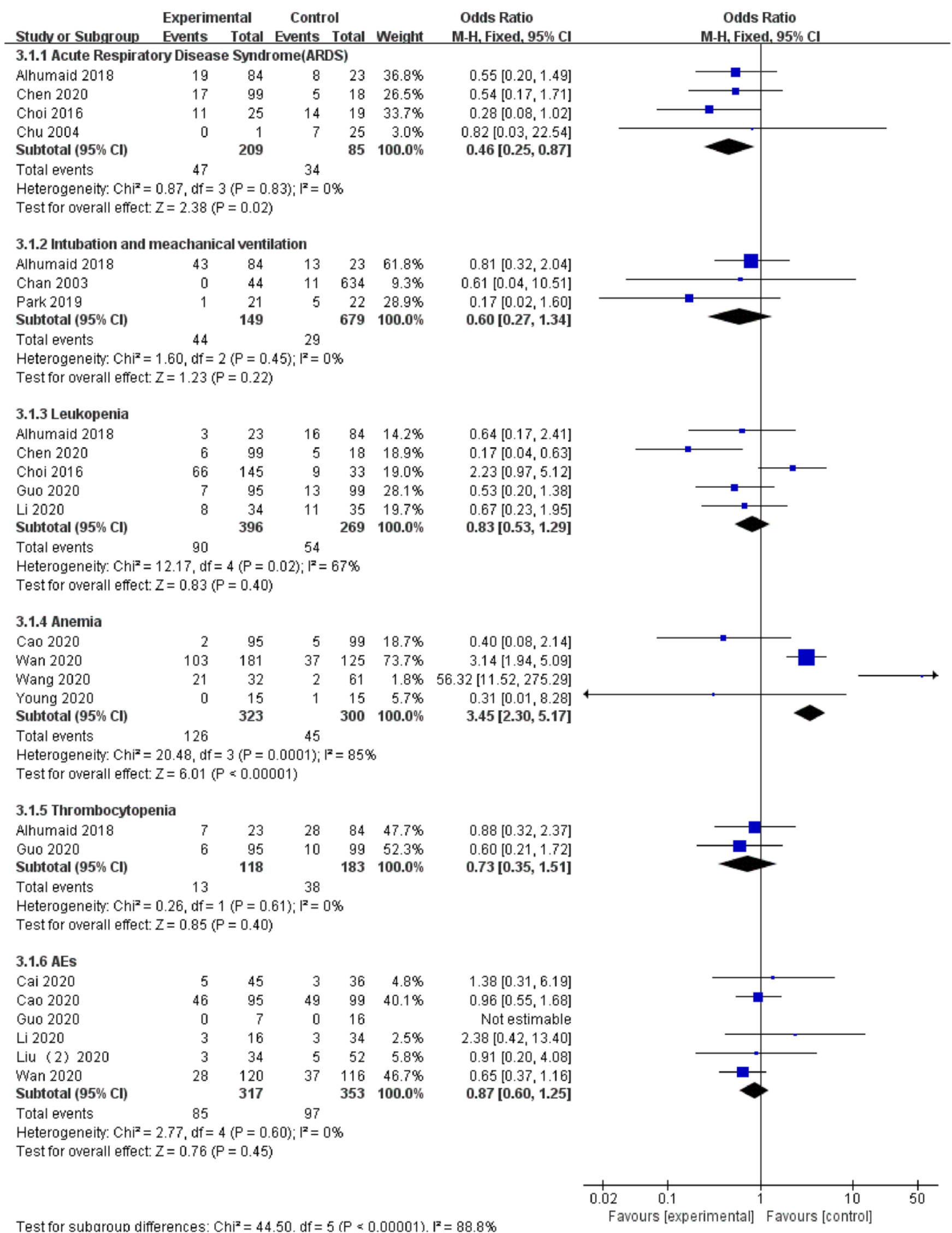

Figure 8. Forest plot of the meta-analysis of LPV/r drug safety assessment. 
clinical trial research data show that LPV/r is effective against SARS-CoV, MERS-CoV and SARS-CoV-2. However, there are also some clinical trials that show that LPV/r has no effect on SARS, MERS and COVID19. This study systematically integrated 18 relevant studies into a meta-analysis. The statistical results show that LPV/r exhibits an effect in patients with early mild SARS, MERS and COVID-19, and LPV/r did not increase the risk of adverse events. However, LPV/r had no effect in severe cases of SARS, MERS and COVID19 and increased the risk of ARDS [19].

The active ingredients of LPV/r include LPV (200 mg) and low-dose RTV (50 mg) [7]. LPV/r was approved by the FDA in 2000 for the treatment of HIV-1 infection in adults and in 2008 for the treatment of HIV-1 infection in children over 2 years old. In China, the pharmacokinetics and clinical safety of LPV/r has been studied, and the drug combination was approved for the treatment of influenza and other respiratory virus infections [39-41]. The identification of an effective antiviral drug is a fundamental strategy in the treatment of coronavirus infections. Due to the urgent need for effective treatments of COVID-19, LPV/r has been increasingly repurposed for immediate use.

Although effective treatments for SARS-CoV-2 are currently lacking, treatment is based on the extremely

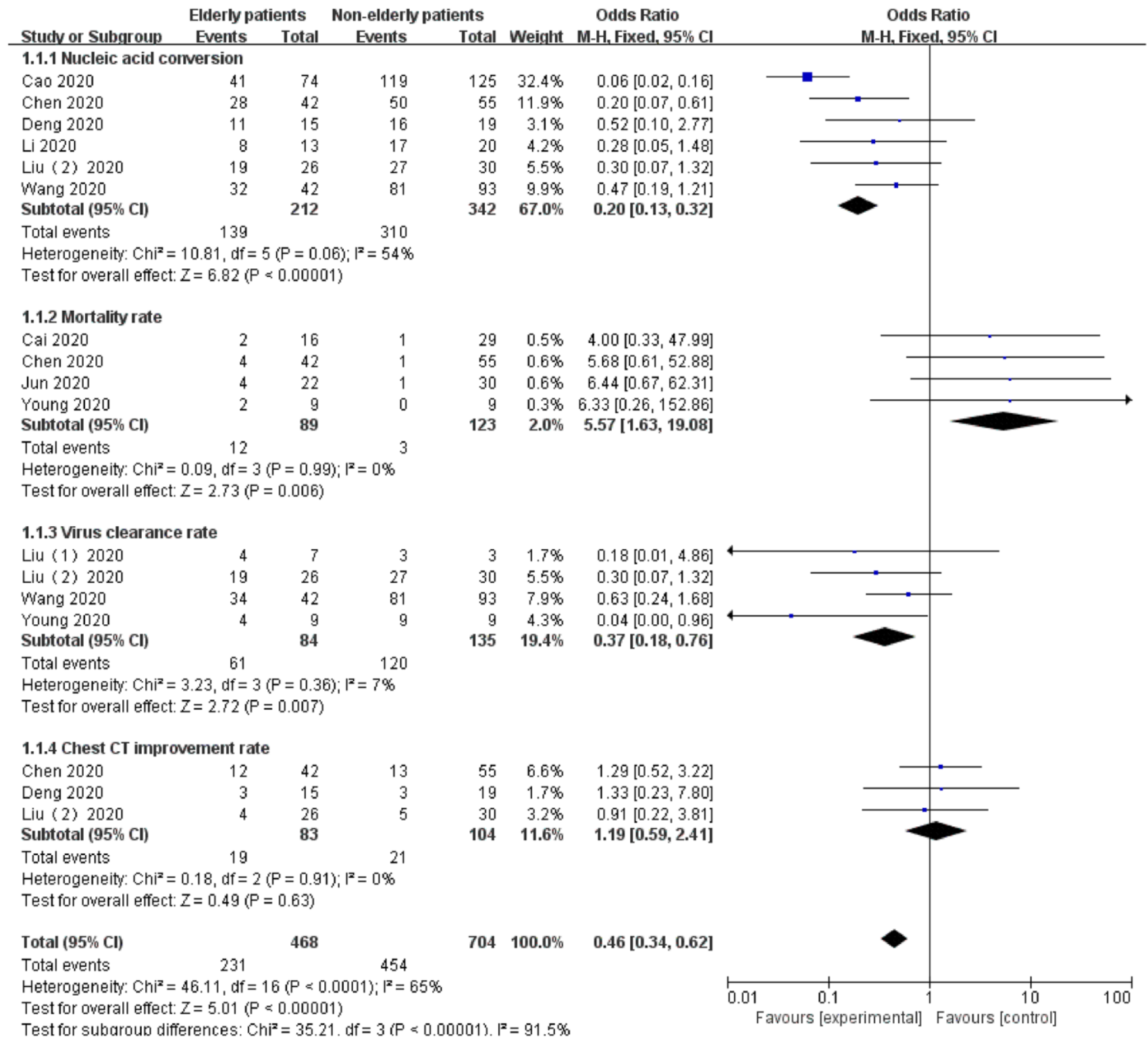

Figure 9. Forest plot of the meta-analysis of age-based differences in effectiveness in LPV/r therapy in patients with COVID-19. 
high sequence homology between SARS-CoV-2 and SARS-CoV in the LPV/r target gene coding. This study analyzed whether LPV/r may represent an effective drug for the treatment of SARS-CoV-2. Clinical research data show that $\mathrm{LPV} / \mathrm{r}$ is not effective in treating severely ill patients. This finding may be attributed to the fact that severely ill patients typically have abnormal liver function, and LPV can aggravate liver damage in the process of inhibiting liver metabolism. Another reason is that systemic

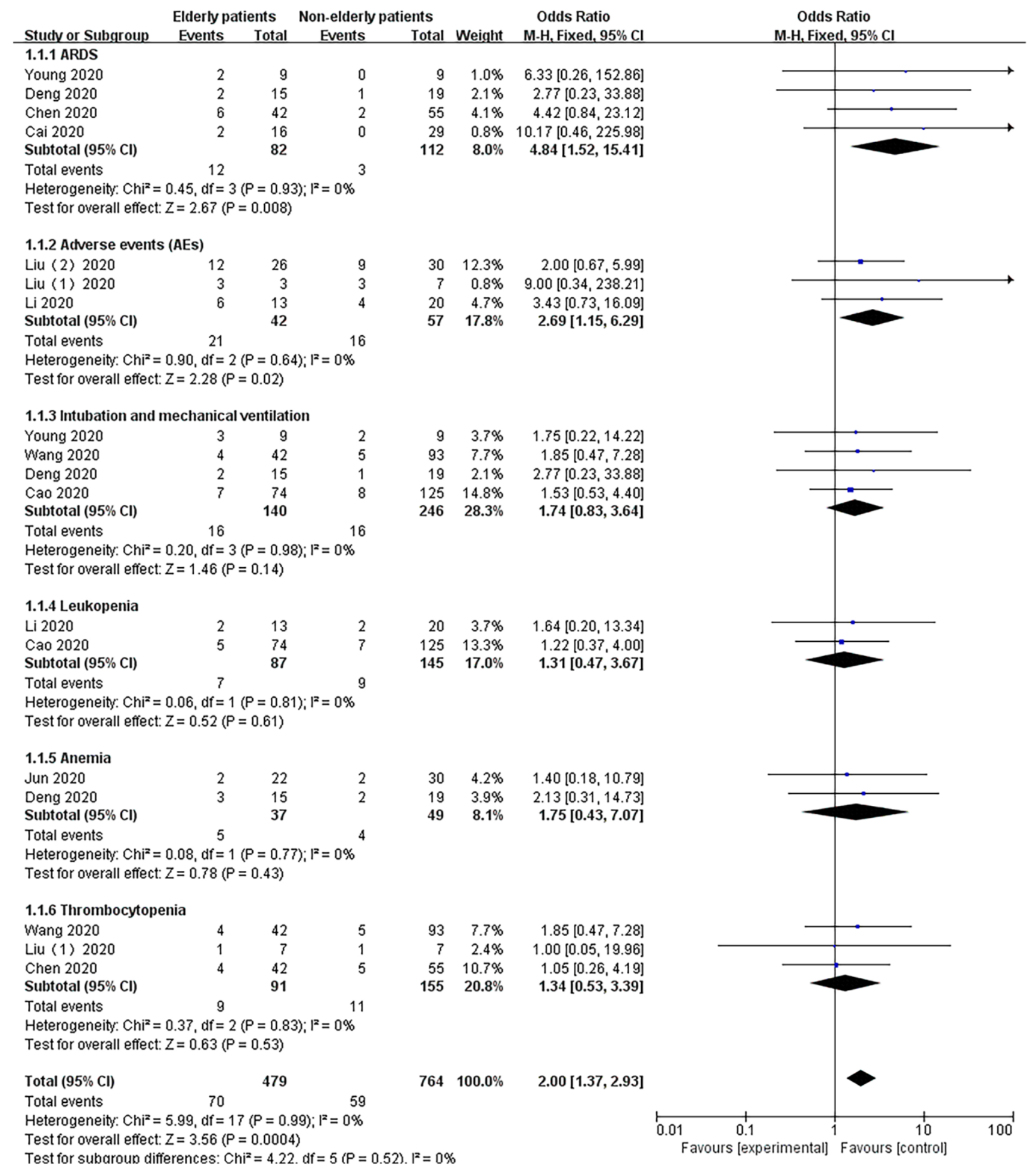

Figure 10. Forest plot of the meta-analysis of age-based differences in safety in LPV/r therapy in patients with COVID-19. 
hyperinflammation rather than viral pathogenicity dominates later stages of SARS-CoV-2. Therefore, other drugs are needed to treat critically ill patients.

We analyzed and evaluated the data of 18 clinical trials. These 18 studies reported mortality data for LPV/r treatment of SARS, MERS and COVID-19. According to the statistical analysis, the LPV/r experimental group exhibited a lower mortality rate than the control group. Five studies reported virus clearance. Seven studies reported the chest CT improvement rate. Six studies reported the viral nucleic acid conversion rate. The results of the statistical analysis showed a significant difference in the virus clearance and nucleic acid conversion rate between the two groups. However, we found no statistically significant differences in the chest CT improvement rate between the LPV/r experimental group and the control group. Few cases of SARS and MERS have been reported. Most cases in our study were COVID-19 cases. Chen et al. comprehensively studied LPV/r in COVID-19 cases and collected chest CT improvement data [29]. This study used a randomized controlled trial

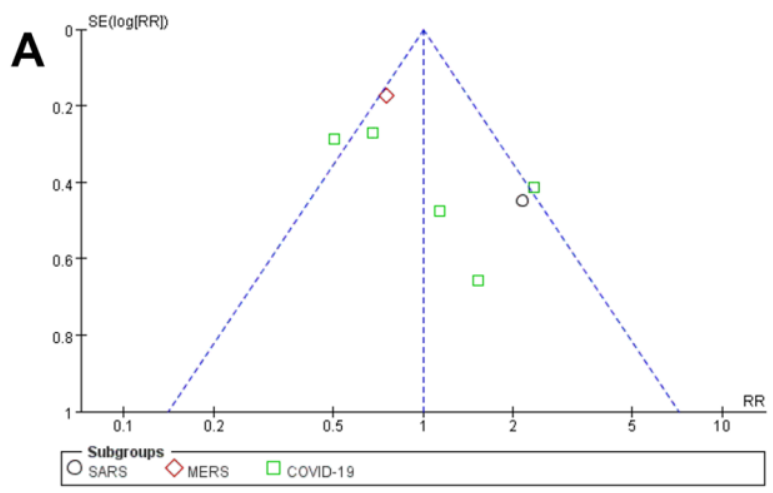

B

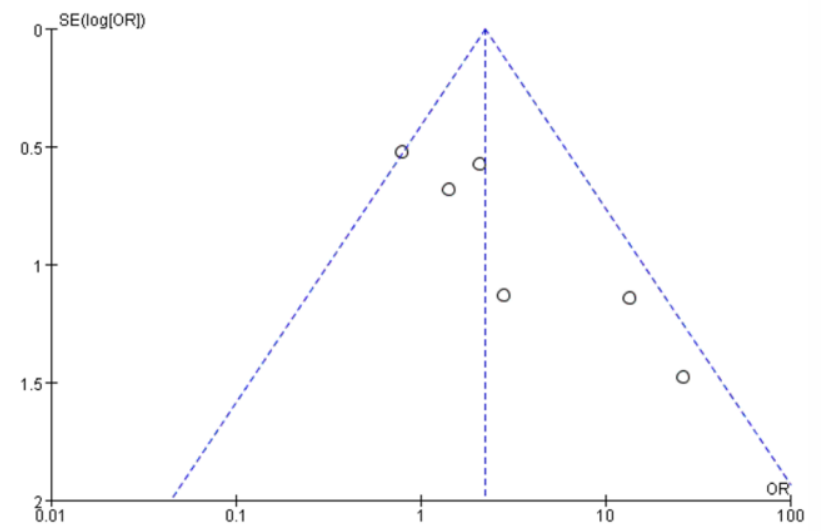

of the standard and LPV/r groups with 99 cases and reported 25 cases with lung CT improvement. Among the 18 cases in the control group that did not use LPV/r antiviral treatment, 4 cases demonstrated chest CT improvement. However, the difference was not statistically significant. Therefore, this study considered that LPV/r could not improve chest CT during antiviral treatment of SARS, MERS and COVID-19, which we hypothesize might be related to irreversible fibrosis of the lungs. Another consideration is that the evaluation of the efficacy of LPV/r cannot be reflected by the chest $\mathrm{CT}$ improvement rate.

We also assessed clinical prognosis outcome data for the LPV/r experimental group and the control group. Four studies reported cases of ARDS. Alhumaid et al. conducted a retrospective observational study of MERS with 19 cases of ARDS among 84 cases of MERS and 8 cases of ARDS among 23 patients in the control group [26]. Chen et al. conducted a randomized controlled study and reported 19 cases of ARDS in 99 cases of COVID-19 [29]. The difference was statistically significant. However, some studies included criteria for

C

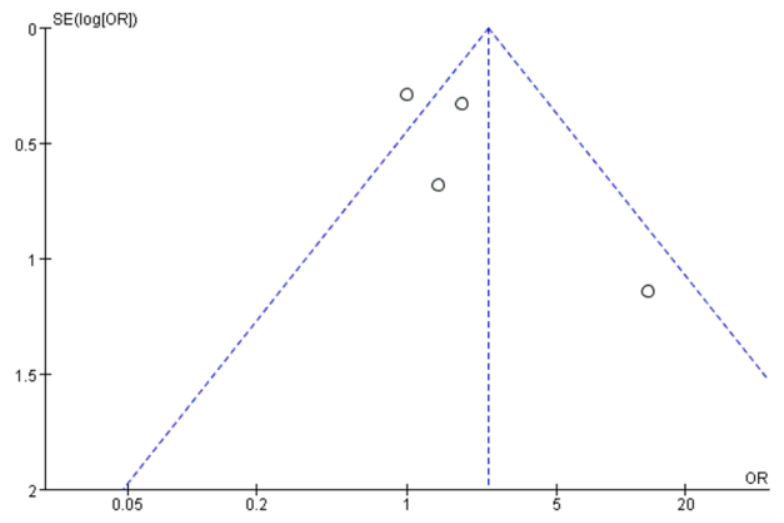

Figure 11. Funnel plot of meta-analysis of publication bias. (A) Funnel plot of publication bias for the efficacy and safety of SARS, MERS, COVID-19 and LPV/ $r$ drugs. (B) publication bias test. (C) Trim and fill methods to test publication bias. 
patients with mild disease, and the LPV/r drug curative effect was unclear in some patients with severe disease. Recently, Wang et al. (Beijing China-Japan Friendship Hospital) [19] published a clinical trial entitled "A trial of lopinavir-ritonavir in adults hospitalized with severe COVID-19" in the NEJM, which included an evaluation of the efficacy and safety of LPV/r. The results of this randomized controlled study suggest that LPV/r is ineffective in patients with severe COVID-19 and may even increase the risk of ARDS complications. This study provides valuable guidance for the first-line treatment of COVID-19. Hu et al conducted a study of the risk factors associated with clinical outcomes in 323 cases of COVID-19. Univariate analysis revealed that among patients receiving LPV/r $\quad(n=28)$, a higher proportion developed unfavorable outcomes, including death or disease progression $(23.8 \%$ versus $5 \%$, $\mathrm{p}<0.001$ ), compared with those not receiving LPV/r $(n=295)$. However, patients with critical disease at baseline were more likely to receive LPV/r than those with nonsevere and severe disease $(\mathrm{p}<0.001)$, indicating that the worse outcomes among those receiving LPV/r could be explained by bias [42].

A total of 6 studies reported adverse events, including nausea, vomiting, and fatigue; these symptoms can be relieved by later treatments and have minimal impact on the disease. Cai et al. conducted a randomized controlled trial with 95 patients in an LPV/r experimental group, and 46 cases of adverse events occurred [35]. In addition, 46 cases of adverse events occurred among the 99 cases in the control group. The statistical results showed no significant difference. Furthermore, both studies suggest that the use of LPV/r in patients with COVID-19 did not increase the risk of adverse events.

Although the WHO accepted the recommendation from the Solidarity Trial's International Steering Committee to discontinue the trial's LPV/r arms, significant findings in previous studies of lopinavir/ritonavir in the treatment of the virus should be analyzed. The recommendation is applicable to a population in hospitalized Solidarity Trial patients and is not applicable in other studies of LPV/r in nonhospitalized patients or as pre- or postexposure prophylaxis for COVID-19 (https://www.who.int/news-room/detail/0407-2020-who-discontinues-hydroxychloroquine-andlopinavir-ritonavir-treatment-arms-for-covid-19).

This paper extracted the latest LPV/r clinical experimental data for statistical analysis. This study not only evaluated the efficacy and safety of LPV/r treatment of COVID-19 but also retrospectively analyzed the previous SARS- and MERS-related LPV/r clinical trials for the treatment of three types of respiratory viruses and an in-depth study of the antiviral mechanism of LPV/r to provide guidance on the use of $\mathrm{LPV} / \mathrm{r}$ in the treatment of the three viruses in the clinic and to evaluate the efficacy of LPV/r and emergency response to adverse events. Furthermore, the incidence of adverse events did not significantly increase. This study analyzed the similarities and differences between $\mathrm{LPV} / \mathrm{r}$ treatments for three respiratory viruses, which has guiding significance for the clinical treatment and control of emergency programs for similar respiratory virus infections in the future.

To our knowledge, this study is the first systematic review and meta-analysis to comprehensively summarize all available evidence to evaluate the efficacy and safety of LPV/r in the treatment of SARS, MERS and COVID-19. The results of this study show that LPV/r may be safely used as a first-line antiviral treatment for COVID-19 in the future. It is of utmost importance to conduct large-scale and high-quality RCTs with high-quality research designs and more studies on the antiviral mechanism of LPV/r to develop better therapeutic regimens.

Relevant studies have reported that LPV/r demonstrates good clinical efficacy in SARS, MERS and COVID-19 and does not increase the risk of adverse events with similar antiviral drugs. Therefore, it is worthwhile to promote the use of LPV/r.

Our results may allow clinicians to comprehensively understand the properties of each anti-coronavirus agent in terms of efficacy and safety outcomes and thus may constitute a basis for drug treatment for COVID-19. It is important to conduct large-scale clinical trials to objectively assess the efficacy of antiviral treatment on the mortality and virological and clinical outcomes of SARS-CoV-2 infections.

This study has several limitations that deserve discussion. First, some studies are still in the stage of clinical trials, and their indicator data reports are incomplete. Second, many types of studies were included, including cohort studies, randomized controlled studies, and case-control studies. Heterogeneity existed in data extraction due to different standards. Moreover, this study may increase the risk of various assessments due to different races, ages, severity of disease and underlying diseases (such as diabetes, HIV infection, and HBV infection).

More recent observational studies and clinical trials of coronavirus therapy, including 214 for lopinavir/ritonavir, are ongoing (available at http:// covid19.trialstracker.net/). Detailed information is provided in Table 1. These trials will provide more 
Table 1. Characteristics of the differences of age and gender in LPV/r therapy in patients with COVID-19.

\begin{tabular}{|c|c|c|c|c|c|c|c|c|}
\hline \multirow{3}{*}{ Study } & \multirow{3}{*}{ Virus type } & \multirow{3}{*}{ Country } & \multicolumn{4}{|c|}{ Age } & \multirow{2}{*}{\multicolumn{2}{|c|}{ Gender }} \\
\hline & & & \multicolumn{2}{|r|}{$<65$} & \multicolumn{2}{|r|}{$>65$} & & \\
\hline & & & $\begin{array}{l}\text { Cardiopulmo } \\
\text { nary disease }\end{array}$ & $\begin{array}{c}\text { No cardiopulmonary } \\
\text { disease }\end{array}$ & $\begin{array}{c}\text { Cardiopulmo } \\
\text { nary disease }\end{array}$ & $\begin{array}{c}\text { No cardiopulmonary } \\
\text { disease }\end{array}$ & Male(\%) & Female $(\%)$ \\
\hline Li 2020 & COVID-19 & China & 3 & 17 & 11 & 2 & $17(51.52 \%)$ & $16(48.48)$ \\
\hline Young 2020 & COVID-19 & Singapore & 2 & 7 & 8 & 1 & $9(50 \%)$ & $9(50 \%)$ \\
\hline Liu (1) 2020 & COVID-19 & China & 2 & 1 & 6 & 1 & $4(40 \%)$ & $6(60 \%)$ \\
\hline Liu (2) 2020 & COVID-19 & China & 12 & 18 & 21 & 5 & $31(55.36 \%)$ & $25(44.64 \%)$ \\
\hline Deng 2020 & COVID-19 & China & 6 & 13 & 13 & 2 & $17(50 \%)$ & $17(50 \%)$ \\
\hline Wang 2020 & COVID-19 & China & 15 & 78 & 38 & 4 & $72(53.33 \%)$ & $63(46.67 \%)$ \\
\hline Cai 2020 & COVID-19 & China & 8 & 21 & 14 & 2 & $21(46.67 \%)$ & $24(53.33 \%)$ \\
\hline
\end{tabular}

Cardiopulmonary disease: including Chronic Obstructive Pulmonary Diseases (COPD), Coronary heart disease (CHD) and hypertension.

evidence for the efficacy and safety of lopinavir/ritonavir or lopinavir/ritonavir combination regimens in patients with COVID-19. Through the discussion and analysis of this study, we provided some recommendations and suggestions for future clinical trials as follows: (1) high-quality RCTs of evidencebased medicine are urgently needed; (2) concurrent therapies, such as other antiviral agents or glucocorticoids, are strictly controlled or balanced; and (3) high-quality research designs, such as clusterrandomized control trials (CRCTs) or a stepped-wedge CRCT design, should be used as much as possible.

Amber et al. found that the severity of COVID-19 largely depends on the patient's age [43]. Adults over 65 years of age represent $80 \%$ of hospitalizations and have a 23-fold greater risk of death than those under 65 years. We not only simply inhibited the virus but also effectively increased the immune responses of older people. In addition, Wang et al. also listed aging as a clinical challenge in patients with COVID-19 and concluded that older patients were more likely to develop poor outcomes and the severe form of the disease [44]. As research continues to develop, Gordan et al. identified biomarkers of biological age as predictors of COVID-19 disease severity [45]. For example, glycan diversity represents one of the main defenses of all higher organisms against pathogens and the repertoire of glycans changes with age. Thus, these researchers suggest that glycans should be the focus of biomarker discovery in COVID-19 cases. This information has greatly promoted the research progress of aging in COVID-19 and has great significance in clinical application. Pang et al. also agrees with the former, suggesting that altered receptor signals in aging and chronic disease play a role in COVID-19 infection and are associated with an increased risk of deterioration in different organs [46]. Thus, they concluded that aging may contribute to the deterioration of COVID-19 in older patients.

\section{CONCLUSIONS}

This study comprehensively evaluated the efficacy and safety of LPV/r in the treatment of SARS, MERS and COVID-19. The purpose of this study was to analyze the data reported by previous studies on LPV/r in the treatment of SARS-CoV and MERS-CoV to explore the application value of $\mathrm{LPV} / \mathrm{r}$ in the clinical treatment of COVID-19. This information offers guiding significance for the selection of first-line clinical treatments. Relevant studies have reported that LPV/r demonstrates good clinical efficacy in SARS, MERS and COVID-19 and does not increase the risk of adverse events compared to similar antiviral drugs. Therefore, its use should be promoted.

LPV/r exhibits good application value in the treatment of respiratory virus infections and HIV infection, and its antiviral effect is significant. Since the FDA approved the drug, LPV/r has played a substantial role in the treatment of respiratory virus and HIV virus infections. In the future, there will be more studies on the antiviral mechanism of LPV/r and new drug research and development in this field.

There will be more large-scale clinical trials of COVID-19 in the future. As these studies progress, researchers will gradually include aging as an indicator to be assessed. The difference in aging in COVID-19 treatment cannot be ignored now and in the future and will have a direct impact on mortality and virus clearance rates in older patients with COVID-19. 
Ethics approval and consent to participate

Our study does not contain data from any individual person or any animals.

\section{Abbreviations}

COVID-19: Coronavirus disease 2019; LPV/r: lopinavir/ritonavir; SARS: severe acute respiratory syndrome; CNKI: China National Knowledge Infrastructure; CBM: China Biomedical Literature Database; NOS: Newcastle-Ottawa Scale; SARS-CoV2: severe acute respiratory syndrome coronavirus 2; MERS-CoV: Middle East respiratory syndrome coronavirus; GEO: Gene Expression Omnibus; HIV-1: human immunodeficiency virus type 1; RCTs: randomized controlled trials; AEs: adverse events; CRCTs: cluster-randomized control trials.

\section{AUTHOR CONTRIBUTIONS}

Liusheng $\mathrm{Wu}$ wrote the manuscript. Yuzhen Zheng and Jixian Liu collected the data. Xiaoqiang $\mathrm{Li}$ and $\mathrm{Da} \mathrm{Wu}$ conceived and guided the study. All authors reviewed, edited and approved the final manuscript. Dingwang $\mathrm{Wu}$ and Pengcheng $\mathrm{Xu}$ contributed to the acquisition, analysis and interpretation of data. All the authors revised it critically for important intellectual content, gave final approval of the version to be published and agreed to be accountable for all aspects of the work. Liusheng Wu, Yuzhen Zheng, Jixian Liu, Xiaoqiang Li and $\mathrm{Da} \mathrm{Wu}$ are joint primary authors. Liusheng $\mathrm{Wu}$, Yuzhen Zheng, Jixian Liu and $\mathrm{Da} \mathrm{Wu}$ contributed equally to this work.

\section{CONFLICTS OF INTEREST}

The authors declare that they have no conflicts of interest.

\section{FUNDING}

Research reported in this publication was supported by the Natural Science Foundation of Guangdong Province of China (Grant No. 2017A030310641), the Science and Technology Innovation Committee of Shenzhen Municipality (Grant No. JCYJ20180228162607111), the Health and Family Planning Commission of Shenzhen Municipality Research Project (Grant No. SZBC2018018), and the China Scholarship Council (CSC, 201908440124).

\section{Editorial Note}

\&This corresponding author has a verified history of publications using the personal email address for correspondence.

\section{REFERENCES}

1. Zhong H, Wang Y, Zhang ZL, Liu YX, Le KJ, Cui M, Yu YT, Gu ZC, Gao Y, Lin HW. Efficacy and safety of current therapeutic options for COVID-19 - lessons to be learnt from SARS and MERS epidemic: A systematic review and meta-analysis. Pharmacol Res. 2020; 157:104872. https://doi.org/10.1016/j.phrs.2020.104872 PMID:32360583

2. Luo $T, N a$, Tan $L$, Jin $P$, Zhao Z, Liang $X$, Tan $L$. The Possibility of Ribavirin in the Treatment of the Coronavirus Disease 2019: A Systematic Review. China Pharmaceuticals. 2020; 29:34-39.

3. Pang W, Wang Qy, Zhao Z. Research progress on corona virus disease 2019 drug therapy. Journal of Clinical Drug Therapy. 2020; 18:24-29.

4. Ford N, Vitoria M, Rangaraj A, Norris SL, Calmy A, Doherty M. Systematic review of the efficacy and safety of antiretroviral drugs against SARS, MERS or COVID-19: initial assessment. J Int AIDS Soc. 2020; 23:e25489.

https://doi.org/10.1002/iia2.25489 PMID:32293807

5. Ye XT, Luo YL, Xia SC, Sun QF, Ding JG, Zhou Y, Chen W, Wang XF, Zhang WW, Du WJ, Ruan ZW, Hong L. Clinical efficacy of lopinavir/ritonavir in the treatment of Coronavirus disease 2019. Eur Rev Med Pharmacol Sci. 2020; 24:3390-96.

https://doi.org/10.26355/eurrev 20200320706 PMID:32271456

6. Yousefi B, Valizadeh S, Ghaffari H, Vahedi A, Karbalaei M, Eslami M. A global treatments for coronaviruses including COVID-19. J Cell Physiol. 2020; 235:9133-42. https://doi.org/10.1002/jcp.29785 PMID:32394467

7. Meini S, Pagotto A, Longo B, Vendramin I, Pecori D, Tascini C. Role of lopinavir/ritonavir in the treatment of covid-19: A review of current evidence, guideline recommendations, and perspectives. J Clin Med. 2020; 9:2050. https://doi.org/10.3390/jcm9072050 PMID:32629768

8. Jun C, Xiuhong X, Ping L, Feng L, Tao L, Zhiyin S, Mei W, Yinzhong $S$, Hongzhou L. Efficacies of lopinavir/ ritonavir and abidol in the treatment of novel coronavirus pneumonia. Chinese Journal of Infectious Diseases. 2020; 38:86-89.

9. San-Juan $R$, Barbero $P$, Fernández-Ruiz $M$, LópezMedrano F, Lizasoáin $M$, Hernández-Jiménez $P$, Silva JT, Ruiz-Ruigómez M, Corbella L, Rodríguez-Goncer I, Folgueira MD, Lalueza A, Batllori E, et al. Incidence and clinical profiles of COVID-19 pneumonia in pregnant women: A single-centre cohort study from Spain. EClinicalMedicine. 2020; 23:100407.

https://doi.org/10.1016/j.eclinm.2020.100407

PMID:32632417 
10. Yan D, Liu XY, Zhu YN, Huang L, Dan BT, Zhang GJ, Gao $\mathrm{YH}$. Factors associated with prolonged viral shedding and impact of lopinavir/ritonavir treatment in hospitalised non-critically ill patients with SARS-CoV-2 infection. Eur Respir J. 2020; 56:2000799.

https://doi.org/10.1183/13993003.00799-2020 PMID:32430428

11. Xiaofeng Z, Huanhuan Y, Congfei W, Gongzhen C, Jian L, Xuefen W, Huili L. Effect of kaletra and arbidol combined with traditional Chinese medicine on renal injury in patients with COVID-19. Health Research. 2020; 40:137-40.

12. Li W, Wang L, Xu Y, Guo J, Zhang C, Liu D, Li J. Drug Utilization Evaluation on Antiviral Treatment in Patients with Severe Coronavirus Disease 2019:Lopinavir/ritonavir. Herald of Medicine. 2020; 39:780-83.

13. Yang M, Gao Y, Zou Y, Zheng Y. Pharmacological recommendations on the off-label use of lopinavir/ritonavir for treatment of coronavirus disease 2019. Chinese Journal of Hospital Pharmacy. 2020; 40:617-21.

14. Yang $\mathrm{P}$, Li C, An W. Adverse Drug Reactions in 45 Patients with COVID-19. Chinese Journal of Pharmacovigilance. 2020; 17:272-75.

15. Zumla A, Hui DS, Perlman S. Middle East respiratory syndrome. Lancet. 2015; 386:995-1007. https://doi.org/10.1016/S0140-6736(15)60454-8 PMID:26049252

16. Cahn P, Andrade-Villanueva J, Arribas JR, Gatell JM, Lama JR, Norton M, Patterson P, Sierra Madero J, Sued O, Figueroa MI, Rolon MJ, and GARDEL Study Group. Dual therapy with lopinavir and ritonavir plus lamivudine versus triple therapy with lopinavir and ritonavir plus two nucleoside reverse transcriptase inhibitors in antiretroviral-therapy-naive adults with HIV-1 infection: 48 week results of the randomised, open label, non-inferiority GARDEL trial. Lancet Infect Dis. $2014 ; 14: 572-80$.

https://doi.org/10.1016/S1473-3099(14)70736-4 PMID:24783988

17. Liang K, Zhang W, Zhang X, Wu Z, Liu Q, Zhang C, Li Z. Analysis of Spread Dynamics of Coronavirus SARS-CoV2, SARS-CoV and MERS-CoV. Journal of University of Electronic Science and Technology of China. 2020; 49:349-56.

18. Zhang $\mathrm{H}$, Chen $\mathrm{H}$, Yang $\mathrm{Y}$, Chen $\mathrm{X}$, Zhang J, Guo B, Peng Z, Li Z, Liu G, Yang B, Chi X, Wang Y, Lu X. Bioinformatics prediction of molecular mechanism and intervention drugs of SARS-related immune injury and their significance for COVID-19 treatment. Chinese Journal of Microbiology and Immunology. 2020;
40:165-73.

19. Cao B, Wang Y, Wen D, Liu W, Wang J, Fan G, Ruan L, Song B, Cai Y, Wei M, Li X, Xia J, Chen N, et al. A trial of lopinavir-ritonavir in adults hospitalized with severe covid-19. N Engl J Med. 2020; 382:1787-99.

https://doi.org/10.1056/NEJMoa2001282 PMID:32187464

20. Lu Z, Fu Z, Huang Z, Huang K, Gao Y, Wang H. Research progress of coronavirus in the 21st century. Journal of Molecular Imaging. 2020; 43:174-78.

21. Chan KS, Lai ST, Chu CM, Tsui E, Tam CY, Wong MM, Tse MW, Que TL, Peiris JS, Sung J, Wong VC, Yuen KY. Treatment of severe acute respiratory syndrome with lopinavir/ritonavir: a multicentre retrospective matched cohort study. Hong Kong Med J. 2003; 9:399-406.

PMID:14660806

22. Chu CM, Cheng VC, Hung IF, Wong MM, Chan KH, Chan KS, Kao RY, Poon LL, Wong CL, Guan Y, Peiris JS, Yuen KY, and HKU/UCH SARS Study Group. Role of lopinavir/ritonavir in the treatment of SARS: initial virological and clinical findings. Thorax. 2004; 59:252-56.

https://doi.org/10.1136/thorax.2003.012658 PMID:14985565

23. Sargiacomo C, Sotgia F, Lisanti MP. COVID-19 and chronological aging: senolytics and other antiaging drugs for the treatment or prevention of corona virus infection? Aging (Albany NY). 2020; 12:6511-17.

https://doi.org/10.18632/aging.103001 PMID:32229706

24. Chen XP, Li GH, Tang XP, Xiong Y, Chen XJ, Cao Y. Lack of severe acute respiratory syndrome in 19 AIDS patients hospitalized together. J Acquir Immune Defic Syndr. 2003; 34:242-43. https://doi.org/10.1097/00126334-200310010-00016 PMID:14526215

25. Choi WS, Kang Cl, Kim Y, Choi JP, Joh JS, Shin HS, Kim G, Peck KR, Chung DR, Kim HO, Song SH, Kim YR, Sohn $K M$, et al, and Korean Society of Infectious Diseases. Clinical presentation and outcomes of Middle East respiratory syndrome in the Republic of Korea. Infect Chemother. 2016; 48:118-26.

https://doi.org/10.3947/ic.2016.48.2.118 PMID:27433382

26. Alhumaid S, Albagshi M, Alrubaya A, Algharib F, Aldera A, Alali J. MERS-CoV transmitted from animal-tohuman vs MERS-CoV transmitted from human-tohuman: comparison of virulence and therapeutic outcomes in a Saudi hospital. Tropical Journal of Pharmaceutical Research. 2020; 17:1155-64. 
https://doi.org/10.4314/tipr.v17i6.23

27. Park SY, Lee JS, Son JS, Ko JH, Peck KR, Jung Y, Woo HJ, Joo YS, Eom JS, Shi H. Post-exposure prophylaxis for Middle East respiratory syndrome in healthcare workers. J Hosp Infect. 2019; 101:42-46.

https://doi.org/10.1016/j.jhin.2018.09.005

PMID:30240813

28. Young BE, Ong SW, Kalimuddin S, Low JG, Tan SY, Loh J, Ng OT, Marimuthu K, Ang LW, Mak TM, Lau SK, Anderson DE, Chan KS, et al, and Singapore 2019 Novel Coronavirus Outbreak Research Team. Epidemiologic features and clinical course of patients infected with SARS-CoV-2 in Singapore. JAMA. 2020; 323:1488-94. https://doi.org/10.1001/jama.2020.3204 PMID:32125362

29. Chen N, Zhou M, Dong X, Qu J, Gong F, Han Y, Qiu Y, Wang J, Liu Y, Wei Y, Xia J, Yu T, Zhang X, Zhang L. Epidemiological and clinical characteristics of 99 cases of 2019 novel coronavirus pneumonia in Wuhan, China: a descriptive study. Lancet. 2020; 395:507-13.

https://doi.org/10.1016/S0140-6736(20)30211-7

PMID: $\underline{32007143}$

30. Lu H. Drug treatment options for the 2019-new coronavirus (2019-nCoV). Biosci Trends. 2020; 14:69-71.

https://doi.org/10.5582/bst.2020.01020

PMID:31996494

31. Liu F, Xu A, Zhang Y, Xuan W, Yan T, Pan K, Yu W, Zhang J. Patients of COVID-19 may benefit from sustained Lopinavir-combined regimen and the increase of Eosinophil may predict the outcome of COVID-19 progression. Int J Infect Dis. 2020; 95:183-91.

https://doi.org/10.1016/j.ijid.2020.03.013

PMID:32173576

32. Deng L, Li C, Zeng Q, Liu X, Li X, Zhang H, Hong Z, Xia J. Arbidol combined with $L P V / r$ versus $L P V / r$ alone against Corona Virus Disease 2019: A retrospective cohort study. J Infect. 2020; 81:e1-5.

https://doi.org/10.1016/j.jinf.2020.03.002

PMID:32171872

33. Liu K, Chen Y, Lin R, Han K. Clinical features of COVID19 in elderly patients: A comparison with young and middle-aged patients. J Infect. 2020; 80:e14-18.

https://doi.org/10.1016/i.jinf.2020.03.005

PMID: $\underline{32171866}$

34. Wan S, Xiang Y, Fang W, Zheng Y, Li B, Hu Y, Lang C, Huang $D$, Sun $Q$, Xiong $Y$, Huang $X$, Lv J, Luo $Y$, et al. Clinical features and treatment of COVID-19 patients in northeast Chongqing. J Med Virol. 2020; 92:797-806. https://doi.org/10.1002/jmv.25783 PMID:32198776

35. Cai Q, Yang M, Liu D, Chen J, Shu D, Xia J, Liao X, Gu Y,
Cai Q, Yang Y, Shen C, Li X, Peng L, et al. Experimental treatment with favipiravir for COVID-19: an open-label control study. Engineering (Beijing). 2020; 6:1192-98.

https://doi.org/10.1016/i.eng.2020.03.007 PMID:32346491

36. Li Y, Xie Z, Lin W, Cai W, Wen C, Guan Y, Mo X, Wang J, Wang $Y$, Peng $P$, Chen X, Hong W, Xiao G, et al. An exploratory randomized controlled study on the efficacy and safety of lopinavir/ritonavir or arbidol treating adult patients hospitalized with mild/moderate COVID-19 (ELACOI). medRxiv. 2020. https://doi.org/10.1101/2020.03.19.20038984

37. Wang Z, Chen X, Lu Y, Chen F, Zhang W. Clinical characteristics and therapeutic procedure for four cases with 2019 novel coronavirus pneumonia receiving combined Chinese and Western medicine treatment. Biosci Trends. 2020; 14:64-68.

https://doi.org/10.5582/bst.2020.01030 PMID:32037389

38. Guo W, Ming F, Dong $Y$, Zhang Q, Zhang X, Mo P, Feng $Y$, Liang K. A Survey for COVID-19 among HIV/AIDS Patients in Two Districts of Wuhan, China. Preprints with The Lancet. 2020.

https://doi.org/10.2139/ssrn.3550029

39. Nukoolkarn V, Lee VS, Malaisree M, Aruksakulwong O, Hannongbua S. Molecular dynamic simulations analysis of ritonavir and lopinavir as SARS-CoV 3CL(pro) inhibitors. J Theor Biol. 2008; 254:861-67.

https://doi.org/10.1016/j.jtbi.2008.07.030 PMID: 18706430

40. Li Y, Jin Y, Ge Q, Liu F, Cheng Y, Yang L, Zhao R. Efficacy and safety of arbidol in the treatment of novel coronavirus pneumonia: a systematic review based on current and previous antiviral therapy. Adverse Drug Reactions Journal. 2020; 22:333-42.

41. Ning $W L$, Luo $W$. Research progress in therapeutic drugs and vaccine of coronavirus disease 2019. Journal of Xiamen University. 2020. 56-61.

42. Hu L, Chen S, Fu Y, Gao Z, Long H, Ren HW, Zuo Y, Wang J, Li H, Xu QB, Yu WX, Liu J, Shao C, et al. Risk factors associated with clinical outcomes in 323 coronavirus disease 2019 (COVID-19) hospitalized patients in Wuhan, China. Clin Infect Dis. 2020; 71:2089-98.

https://doi.org/10.1093/cid/ciaa539 PMID:32361738

43. Mueller AL, McNamara MS, Sinclair DA. Why does COVID-19 disproportionately affect older people? Aging (Albany NY). 2020; 12:9959-81. https://doi.org/10.18632/aging.103344 PMID: $\underline{32470948}$ 
44. Wang L, Sun Y, Yuan Y, Mei Q, Yuan X. Clinical challenges in cancer patients with COVID-19: Aging, immunosuppression, and comorbidities. Aging (Albany NY). 2020; 12:24462-74.

https://doi.org/10.18632/aging.104205

PMID:33232275

45. Lauc G, Sinclair D. Biomarkers of biological age as predictors of COVID-19 disease severity. Aging (Albany NY). 2020; 12:6490-91. https://doi.org/10.18632/aging.103052

PMID: $\underline{32268300}$

46. Pang L, Liu Y, Shen M, Ye J, Chen R, Lan Z, Wu Z, Guo Y, Zhang P. Influence of aging on deterioration of patients with COVID-19. Aging (Albany NY). 2020; 12:26248-62. https://doi.org/10.18632/aging.202136

PMID:33232272 


\section{SUPPLEMENTARY MATERIALS}

\section{Supplementary Tables}

Please browse Full Text version to see the data of Supplementary Tables 1, 2.

Supplementary Table 1. Characteristics of included studies.

Supplementary Table 2. Clinical trials of LPV/r against COVID-19 registered on ClinicalTrials.gov. 